\title{
Investigation of the Biochemical and Histological Changes Induced by Zearalenone Mycotoxin on Liver in Male Mice and the Protective Role of Crude Venom Extracted from Jellyfish Cassiopea Andromeda
}

\author{
Madeha Al-Seeni ${ }^{1}$, Nagwa El-Sawi ${ }^{2}$,Soad Shaker ${ }^{3}$, Asma Al-Amoudi ${ }^{1}$ \\ ${ }^{1}$ Biochemistry Department, Faculty of Science, King Abdulaziz University, Jeddah, Saudi Arabia; ${ }^{2}$ Chemistry Department, Faculty \\ of Science, Sohag University, Sohag, Egypt; ${ }^{3}$ Histology, Medicine Faculty, King Abdulaziz University, Jeddah, Saudi Arabia. \\ Email: dr_nelsawi@yahoo.com \\ Received February $1^{\text {st }}, 2011$; revised March $3^{\text {rd }}, 2011$; accepted March $8^{\text {th }}, 2011$.
}

\begin{abstract}
Zearalenone (ZEN) is a non steroidal estrogenic mycotoxin produced by Fusarium species of fungi which contaminate human foods and animal feeds worldwide. In this study hepatotoxicity of ZEN was evaluated in mice by oral administration of single and repeated doses of ZEN mycotoxin $(2.7 \mathrm{mg} / \mathrm{kg} \mathrm{b.w.).} \mathrm{The} \mathrm{protective} \mathrm{effect} \mathrm{of} \mathrm{crude} \mathrm{venom} \mathrm{ex-}$ tracted from jellyfish Cassiopea andromeda was also assessed. Mice were divided into four groups $(N=10)$. G1: receiving the toxin once and sacrificed 48 h later, G2: toxin administered twice for one week, G3: toxin administered twice a week for two weeks, G4: pretreated orally by a single dose of crude venom $(1.78 \mathrm{mg} / 20 \mathrm{~g}) 24$ hours prior to administration of ZEN twice a week for two weeks. Each treated group had its corresponding control which received $1 \%$ DMSO saline. ZEN treatment significantly increased alanine aminotransferase (ALT), aspartateaminotrnsferase $(A S T)$ and alkaline phosphatase (ALP) activities after 48 hours and two weeks, while ALT was also significantly increased after one week. Tumor necrosis factoralpha $(T N F-\alpha)$ level was undetected in treated and control groups except the group treated with ZEN for one week. Alphafetoprotein (AFP) level was increased significantly only after two weeks. The activity of antioxidants was significantly increased in all groups. ZEN was also found to modify the serum proteins especially gamma-globulin which showed a significant decrease after $48 \mathrm{~h}$ and two weeks. Improvement in liver function occurred in the group pretreated with the crude venom, and AFP and antioxidants returned to normal level, while $T N F-\alpha$ level was also undetected. Gamma globulin was significantly increased. The recovery observed in the group which was pretreated with crude venom may related to bradykinin content of this venom which exhibits a hepatoprotective effect. Histological changes in mouse liver coincided with biochemical changes. In conclusion, this study revealed that ZEN induced liver function and structural changes promising an approach for using a crude venom of jellyfish to enhance liver function.
\end{abstract}

Keywords: Mycotoxin, Zearalenone, Liver, Mice, Jellyfish Crude Venom

\section{Introduction}

Zearalenone (ZEN) (previously known as F-2 toxin) is a non steroidal oestrogenic mycotoxin biosynthesized through a polyketide pathway by a variety of Fusariumfungi, including $F$. graminearum, $F$. culmorum, $F$. cerealis, $F$. equiseti, $F$. crookwellenseand $F$. semitectum, which are common soil fungi, in temperate and warm countries, and are regular contaminants of cereal crops worldwide
[1]. Zearalenone is implicated in reproductive disorders of farm animals [2-4] and in hyperestrogenic syndroms in humans [5]. Zearalenone is mainly metabolized in the liver with the production of twoessential metabolites $\alpha$-zearalenol and $\beta$-zearalenol [6]. Alpha zearalenol possesses a ten-times higher estrogenic activity than ZEN [7]. The estrogenic effect of ZEN may relate to the increased incidence of hepatocellular adenomas in mice [8]. To date there has been much research into the venoms of 
jellyfish which attract significant medical attention, such as the box jellyfish (Chironexfleckeri) and the irukandji (Carukiabarnesi) and blue jellyfish (Catostylusmosaicus) in the hope of finding antivenom, or a molecule or peptide of medical importance [9]. The toxins of these coelenterates had been detected to include bradykinin and related polypeptides which have a kinin-like action [10]. Bradykinin has been found to exert hepatoprotective effects in rodents. According to Abu-Amra and Abd El-rehim [11], the extracted crude venom of Jelly fish, Cassiopea Andromeda stimulates the cellular proliferation of white mice duodenum. It activates liver cells by increasing the metabolic rate [12]. Also, Abdel-Rehim [13] proved a protective effect of this crude venom in case of gastric ulceration evoked by indomethacin. In the present study, the effect of ZEN on the liver was investigated, because the hepatocytes constitute a target system for zearalenone toxicity $[14,15]$. Further, the protective influence of the crude venom extracted from jellyfish Cassiopea Andromeda against the toxic action of ZEN was also estimated.

\section{Materials and Methods}

\subsection{Chemicals}

Zearalenone $(5 \mathrm{mg}$ ) was purchased as pure crystal from BioAustralis fine chemicals (Smithfield, NSW, Australia). Crude venom separated from the jelly fish Cassiopia Andromeda from Red sea [1] was a kind gift from Prof. Soheir A. Abdel-Rehim, Department of Zoology, Toxicology laboratory, SohagUniversity, Sohag, Egypt.

\subsection{Animals and Treatment}

Seventy inbred, adult ( 8 weeks old) male Balb/c mice weighing 20 - $30 \mathrm{~g}$ were obtained from King Fahd Medical Research Center, King AbdulAziz University, Jeddah, Saudi Arabia. The animals were conditioned for two weeks at room temperature. A commercial balanced diet and tap water, ad labium was provided throughout the experiment. ZEN was dissolved in DMSO and diluted to $1: 100$ in a sterile saline solution $(0.9 \% \mathrm{NaCl})$ to produce a working stock which was stored at $4^{\circ} \mathrm{C}$. Crude venom of $46.2 \mathrm{mg}$ was dissolved in $10 \mathrm{ml}$ distilled water to produce a working stock and stored at $4{ }^{\circ} \mathrm{C}$ [16]. Animals were distributed randomly into seven groups among them, three are control groups and four tested groups. All the mice in the control groups were subjected to oral administration of $1 \%$ DMS and the other four groups were given oral doses of ZEN toxin as described below:

C1: Mice given orally $1 \mathrm{ml}$ of $1 \%$ DMSO saline and left for 48 hours.

T1: Mice given orally $2.7 \mathrm{mg} / \mathrm{kg}$ b.w. of ZEN and left 48 hours.
C2: Mice given orally $1 \mathrm{ml}$ of $1 \%$ DMSO saline twice a week for 1 week.

T2: Mice given orally $2.7 \mathrm{mg} / \mathrm{kg}$ b.w. of ZEN twice a week for 1 week.

C3: Mice given orally $1 \mathrm{ml}$ of $1 \%$ DMSO saline twice a week for 2 weeks.

T3: Mice given orally $2.7 \mathrm{mg} / \mathrm{kg}$ b.w. of ZEN twice a week for 2 weeks.

T4: Mice given a dose of $1.78 \mathrm{mg} / 20 \mathrm{~g}$ b.w. of jellyfish crude venom, then after $24 \mathrm{~h}$, given orally $2.7 \mathrm{mg} / \mathrm{kg}$ b.w. of ZEN twice a week for 2 weeks. At the end of each specified period, mice were anesthetized using diethyl ether and dissected. Blood samples from all groups were collected from the orbital sinus [17], in plain tubes and centrifuged at $1000 \mathrm{rpm}$ for $15 \mathrm{~min}$ to separate the serum, then divided into several aliquots and stored at $-20^{\circ} \mathrm{C}$ until analysis was performed. After the collection of blood samples, anaesthetized animals were sacrificed by cervical dislocation. The abdomen was op in sterile ened and the liver was rapidly dissected out, washed in sterile saline and fixed in $10 \%$ buffered formalin for histopathological studies.

\subsection{Biochemical Assays}

2.3.1. Determination of ALT, AST and ALP Activities Spectrometric diagnostic kits were used to assess the activities of ALT, AST and ALP. The results were automatically calculated by VITROS 250 system analyzer (Ortho Clinical Diagnostics, a Johnson and Johnson company, Rochester, NY, U.S.A.).

\subsubsection{Determination of AFP Concentration}

Mouse AFP ELISA kit (Uscn Life Science, Wuhan, China) was used to determine AFP concentration in sera of mice.

\subsubsection{Determination of TNF- $\alpha$}

TNF- $\alpha$ was assayed using mouse TNF- $\alpha$ ELISA kit ((Biovendor, Modrice, Czech Republic).

\subsubsection{Determination of Antioxidants}

Antioxidants activity was evaluated using a spectrometric kit (Cayman Chemical Company, Ann Arbor, Michigan, USA).

\subsubsection{Determination of Serum Protein}

The percentages of albumin and globulins were determined according to Helena serum protein procedure (Helena Laboratories, Beaumont, Texas, USA).

\subsubsection{Preparation of Liver Section and Histopathological Examination}

Small pieces of the large lobes of livers $2 \times 2 \mathrm{~mm}$ were washed by saline, re-fixed in $10 \%$ buffered formalin and then, embedded in paraffin. Sections of tissues were cut 
at $0.5 \mu \mathrm{m}$ and mounted on slides. The slides were stained with haematoxylin and eosin. The procedures of preparation and staining were done according to Drury and Wallington [18]. Stained sections were examined and photographed using digital camera, attached to Olympus CX21 light microscope and connected to computer.

\subsubsection{Statistical Analysis}

Statistical analysis was performed using the Statistical Package for Social Science (SPSS for windows, version 12) (SPSS Inc., Chicago, IL, U.S.A.). The variability degree of the results is expressed as mean \pm standard error of means (Mean \pm S.E.). The significance of the difference between samples was determined using Mann-Whitney and One-Way Anova tests. The difference was regarded significant when $0.01 \leq P<0.05$, highly significant when $P<0.01$ and non-significant when $P>0.05$, where $P$ is a level of significance.

\section{Results}

\subsection{Liver Enzymes ALT, AST and ALP}

There was a highly significant increase $(P<0.01)$ in the mean value of ALT after forty eight hours (T1), one week (T2), two weeks (T3) and crude venom pretreated group (T4) compared with controls. The crude venom pretreated group showed a high significant decrease $(P<$ 0.01 ) of ALT activity compared to ZEN treated groupafter two weeks. The results of AST and ALP activities $(\mathrm{U} / \mathrm{L})$ revealed a highly significant increase $(P<0.01)$ after forty eight hours and two weeks compared with controls. On the other hand, there is no significant difference $(P>0.05)$ after one week and in crude venom pretreated group relative to controls. A high significant decrease $(P<0.01)$ of AST activity was noticed in the group pretreated with the crude venom compared with that treated only by ZEN after two weeks (T3) (Table 1).

\subsection{Alphafetoprotein (AFP)}

AFP concentration $(\mathrm{ng} / \mathrm{ml})$ was highly significantly increased $(P<0.01)$ only after two weeks, while a high significant decrease $(P<0.01)$ of AFP concentration was noted in crude venom pretreated group (T4) in comparison with that treated only by ZEN after two weeks (T3) (Table 2).

\subsection{Tumor Necrosis Factor Alpha (TNF- $\alpha$ )}

The level of TNF- $\alpha(\mathrm{pg} / \mathrm{ml})$ was undetected in all groups except the group treated with ZEN twice a week for one week (Table 2).

\subsection{Antioxidants}

The concentration of antioxidants has significant increase
Table 1. Effect of zearalenone (2.7 mg/kg b.w.) on liver enzymes.

\begin{tabular}{cccc}
\hline Groups & ALT (U/L) & AST (U/L) & ALP (U/L) \\
\hline $\mathbf{C}_{\mathbf{1}}$ & $20.75 \pm 0.89$ & $59.13 \pm 0.33$ & $83.02 \pm 0.64$ \\
$\mathbf{T}_{\mathbf{1}}$ & $33.51 \pm 0.32^{* *}$ & $83.38 \pm 0.66^{* *}$ & $201.51 \pm 0.32^{* *}$ \\
$\mathbf{C}_{\mathbf{2}}$ & $23.76 \pm 0.16$ & $51.29 \pm 0.55$ & $82.05 \pm 0.77$ \\
$\mathbf{T}_{\mathbf{2}}$ & $41.20 \pm 0.79^{* *}$ & $51.02 \pm 0.64$ & $83.02 \pm 0.64$ \\
$\mathbf{C}_{3}$ & $21.76 \pm 0.16$ & $57.81 \pm 0.36$ & $84.85 \pm 0.72$ \\
$\mathbf{T}_{3}$ & $33.51 \pm 0.32^{* *}$ & $90.19 \pm 0.34^{* *}$ & $106.25 \pm 0.80^{* *}$ \\
$\mathbf{T}_{4}$ & $29.35 \pm 0.81^{* *}, \ldots$ & $58.43 \pm 0.36^{\# \#}$ & $84.18 \pm 0.65^{\# \#}$ \\
\hline
\end{tabular}

Values are expressed as mean of 10 mice \pm S.E. C: control group; T: treated group; $\mathrm{C}_{1}$ : received $1 \mathrm{ml}$ of $1 \%$ DMSO saline and left 48 hours; $\mathrm{C}_{2}$ : received $1 \mathrm{ml}$ of $1 \%$ DMSO saline twice a week for one week; $\mathrm{C}_{3}$ : received $1 \mathrm{ml}$ of $1 \%$ DMSO saline twice a week for two week; $T_{1}$ : received 1 dose of ZEN and left 48 hours; $T_{2}$ : received ZEN twice a week for 1 week; $T_{3}$ : received ZEN twice a week for 2 weeks; $T_{4}$ : received 1 dose of crude venom $(1.78 \mathrm{mg} /$ 20 g b.w.) 24 hours prior to receiving ZEN twice a week for 2 weeks; $* * P<$ 0.01 vs. respective control; ${ }^{*} P<0.05$ vs. respective control; ${ }^{\# \#} P<0.01$ vs. $\mathrm{T}_{3}$.

Table 2. Effect of zearalenone $(2.7 \mathrm{mg} / \mathrm{kg} \mathrm{b.w.)}$ on AFP, TNF- $\alpha$ and antioxidants.

\begin{tabular}{cccc}
\hline Groups & AFP (ng/ml) & TNF- $\boldsymbol{\alpha}(\mathbf{p g} / \mathbf{m l})$ & $\begin{array}{c}\text { Antioxidant } \\
(\mathbf{m M})\end{array}$ \\
\hline $\mathbf{C}_{\mathbf{1}}$ & $0.18 \pm 0.02$ & $<\mathrm{LOD}$ & $0.38 \pm 0.003$ \\
$\mathbf{T}_{\mathbf{1}}$ & $0.21 \pm 0.07$ & $<\mathrm{LOD}$ & $0.46 \pm 0.03^{*}$ \\
$\mathbf{C}_{\mathbf{2}}$ & $0.26 \pm 0.01$ & $<\mathrm{LOD}$ & $0.43 \pm 0.01$ \\
$\mathbf{T}_{\mathbf{2}}$ & $0.63 \pm 0.17$ & $45.32 \pm 0.56$ & $0.60 \pm 0.01^{* *}$ \\
$\mathbf{C}_{\mathbf{3}}$ & $0.1 \pm 0.00$ & $<\mathrm{LOD}$ & $0.50 \pm 0.002$ \\
$\mathbf{T}_{\mathbf{3}}$ & $1.34 \pm 0.20^{* *}$ & $<\mathrm{LOD}$ & $0.55 \pm 0.03^{*}$ \\
$\mathbf{T}_{\mathbf{4}}$ & $0.27 \pm 0.01^{\# \#}$ & $<\mathrm{LOD}$ & $0.48 \pm 0.01^{\#}$ \\
\hline
\end{tabular}

Values are expressed as mean of 10 mice \pm S.E. Limit of detection (LOD); C: control group; $\mathrm{T}$ : treated group; $\mathrm{C}_{1}$ : received $1 \mathrm{ml}$ of $1 \%$ DMSO saline for 48 hours; $\mathrm{C}_{2}$ : received $1 \mathrm{ml}$ of $1 \%$ DMSO saline twice a week for one week; $C_{3}$ : received $1 \mathrm{ml}$ of $1 \%$ DMSO saline twice a week for two week; $T_{1}$ : received 1 dose of ZEN and left 48 hours; $T_{2}$ : received ZEN twice a week for 1 week; $T_{3}$ : received ZEN twice a week for 2 week; $T_{4}$ : received 1 dose of crude venom $(1.78 \mathrm{mg} / 20 \mathrm{~g} \mathrm{b.w}) 24$ hours prior to receiving ZEN twice a week for two week; $* * P<0.01$ vs. respective control; $* P<0.05$ vs. respective control; ${ }^{\#} P<0.01$ vs. $\mathrm{T}_{3}{ }^{\#} P<0.05$.

\subsection{Serum Proteins}

The percentages of albumin and $\alpha 1$-globulin were highly significantly increased $(P<0.01)$ after forty eight hours (T1), while a high significant decrease $(P<0.01)$ of $\alpha 2, \beta$ and $\gamma$ globulins was observed in the mean values compared to the control. The significant increase $(P<0.05)$ of albumin and $\alpha 1$-globulin were observed after one week (T2) relative to control, whereas there were no significant difference $(P>0.05)$ of $\alpha 2, \beta$ and $\gamma$-globulins. On the other hand, a high significant decrease $(P<0.01)$ of albumin and $\alpha 1$-globulin was noticed after two weeks 
(T3) compared to corresponding control. The percentage of $\beta$-globulin was highly significantly increased $(P<$ $0.01)$ and $\gamma$-globulin exhibits a high significant decrease $(P<0.01)$ after two weeks compared to control. In the crude venom pretreated group (T4), percentages of albumin and $\alpha 1$-globulin were highly significantly decreased $(P<0.01)$ compared to control. Otherwise, there was a high significant increase $(P<0.01)$ of $\beta$-globulin and $\gamma$-globulin compared to control, But when crude venom pretreated group compared with that only treated with ZEN for two weeks, there is no significant difference $(P>0.05)$ of albumin, $\alpha 1$ and $\alpha 2$ globulins has been found while $\beta$ fraction shows a high significant decrease $(P<0.01)$ and $\gamma$-globulin was highly significantly increased $(P<0.01)$ (Table 3).

\subsection{Histopathological Results}

Liver sections in the control groups showed that hepatocytes arranged in cell cords separated by thin wall blood sinusoids. Their lining epithelium consists of flat endothelial cells and the cytoplasm is acidophilic with basophilic regions and there is no histopathological changes were noticed (Figure 1(a)). After 48 hours of administration of ZEN, marked hepatocytes swelling, obliterating the intervening blood sinusoids and deep stained small nuclei were observed. Apoptotic cells with preserved outlines, and shrunken dark stained cytoplasm were frequently seen. Other hepatocytes exhibit necrosis (degeneration of cytoplasmic contents) with loss of cellular outlines (Figure 1(b)).In the Livers of the group given ZEN twice a week for one week, binucleated cells and karyomegaly (large sized nuclei) are more frequent. Cells with 3 or 4 nuclei (polyploidy) were commonly seen throughout liver lobules. Cytoplasm of most cells showed tiny rounded vacuoles, most probably lipid droplets (Figure 1(c)). Congestion in portal and central ve- ins (Figure 1(d)) was the most characteristic feature of the group treated with ZEN twice a week for two weeks. Focal alteration in hepatocytes shape and arrangement was also noticed and the cells seemed swollen with irregular outlines (Figure 1(e)). The liver parenchyma in the crude venom pretreated group looked more or less normal except of few cells still showed binuclei. Tiny vacuoles (lipids) within hepatocytes were also among the observed features and others exhibit karyomegaly (Figure 1(f)).

(a) Liver section of the control group did not show histopathological changes showed two central veins (CV) and portal area demarcated by presence of portal vein $(\mathrm{PV})$ and bile duct (BD). (b) Liver section of the group given a single dose of ZEN and left for $48 \mathrm{~h}$ shows marked hepatocytes swelling and degeneration of cytoplasmic contents (white arrows) obliterating the intervening blood sinusoids (stars). Few cells showed dark stained cytoplasm as an early sign of apoptosis (thin arrows). (c and d) Liver sections of the group given ZEN twice a week for one week, (c) showed Karyomegaly (whitearrow) and cell with multiple nuclei (polyploidy) are frequent finding (black arrow). Notice also the augmented nuclei of sinusoidal von Kupffer phagocytes cells, (d) an increase in binucleated hepatocytes (thin arrows). Cells with large sized nuclei(karyomegaly) are also observed (white arrow) nevertheless some areas showed necrosis (stars).(e) and (f) Liver sections of the group given ZEN twice a week for two weeks, (e) Low magnification to show congestion in portal and central veins, (f) focal alteration inhepatocytes shape and arrangement. The cells are swollen with irregular outlines. Nuclei of many cells showed karyolysis or even disappeared (thin arrows). Cells with large size dnuclei (karyomegaly) (white arrows). (g) Liver section of the group pretreated with crude venom of jellyfish crude venom twenty 24

Table 3. Effect of zearalenone $(2.7 \mathrm{mg} / \mathrm{kg} \mathrm{b.w.)} \mathrm{on} \mathrm{serum} \mathrm{proteins.}$

\begin{tabular}{cccccc}
\hline Groups & Albumin (\%) & $\boldsymbol{\alpha}_{\mathbf{1}}$-globulin (\%) & $\boldsymbol{\alpha}_{\mathbf{2}}$-globulin (\%) & $\boldsymbol{\beta}$-globulin (\%) & $\boldsymbol{\gamma}$-globulin (\%) \\
\hline $\mathbf{C}_{\mathbf{1}}$ & $48.81 \pm 0.35$ & $5.36 \pm 0.05$ & $17.72 \pm 0.16$ & $22.51 \pm 0.27$ & $5.82 \pm 0.44$ \\
$\mathbf{T}_{\mathbf{1}}$ & $53.87 \pm 0.25^{* *}$ & $6.34 \pm 0.11^{* *}$ & $16.98 \pm 0.09^{* *}$ & $19.22 \pm 0.26^{* *}$ & $3.59 \pm 0.07^{* *}$ \\
$\mathbf{C}_{\mathbf{2}}$ & $47.07 \pm 0.07$ & $7.34 \pm 0.20$ & $20.84 \pm 0.06$ & $21.31 \pm 0.16$ & $2.85 \pm 0.04$ \\
$\mathbf{T}_{\mathbf{2}}$ & $48.85 \pm 0.35^{*}$ & $8.40 \pm 0.28^{*}$ & $20.55 \pm 0.26$ & $20.87 \pm 0.45$ & $2.77 \pm 0.15$ \\
$\mathbf{C}_{\mathbf{3}}$ & $51.48 \pm 0.45$ & $7.17 \pm 0.16$ & $19.91 \pm 0.61$ & $18.05 \pm 0.06$ & $2.99 \pm 0.09$ \\
$\mathbf{T}_{\mathbf{3}}$ & $48.38 \pm 0.03^{* *}$ & $5.96 \pm 0.16^{* *}$ & $20.91 \pm 0.03$ & $22.97 \pm 0.19^{* *}$ & $1.82 \pm 0.03^{* *}$ \\
$\mathbf{T}_{\mathbf{4}}$ & $48.82 \pm 0.35^{* *}$ & $5.81 \pm 0.26^{* *}$ & $19.96 \pm 0.16$ & $19.14 \pm 0.12^{* *}, \ldots$ & $6.27 \pm 0.28^{* *}, \ldots *$ \\
\hline
\end{tabular}

Values are expressed as mean of 10 mice \pm S.E. C: control group; T: treated group; $\mathrm{C}_{1}$ : received $1 \mathrm{ml}$ of $1 \%$ DMSO saline for 48 hours; $\mathrm{C}_{2}$ : received $1 \mathrm{ml}$ of $1 \%$ DMSO saline twice a week for one week; $\mathrm{C}_{3}$ : received $1 \mathrm{ml}$ of $1 \%$ DMSO saline twice a week for two week; $\mathrm{T}_{1}:$ received 1 dose of ZEN and left 48 hours; $\mathrm{T}_{2}$ : received ZEN twice a week for 1 week; $T_{3}$ : received ZEN twice a week for 2 weeks; $T_{4}$ : received 1 dose of crude venom ( $1.78 \mathrm{mg} / 20 \mathrm{~g}$ b.w.) 24 hours prior to receiving ZEN twice a week for two weeks; ${ }^{*} P<0.01$ vs. respective control; ${ }^{*} P<0.05$ vs. respective control; ${ }^{\# \prime} P<0.01$ vs. $T_{3}$. 

and the Protective Role of Crude Venom Extracted from Jellyfish Cassiopea Andromeda

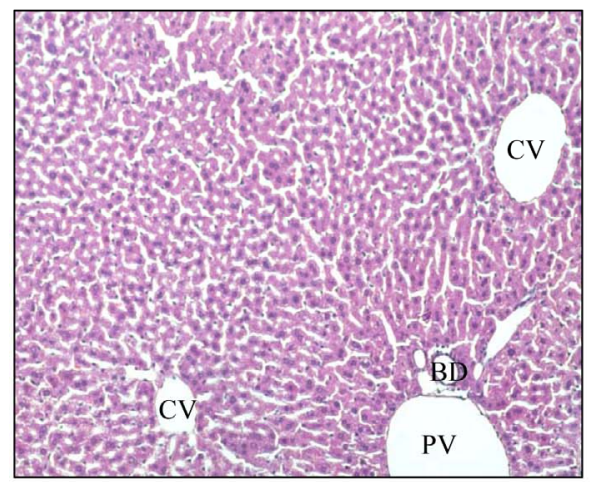

(a)

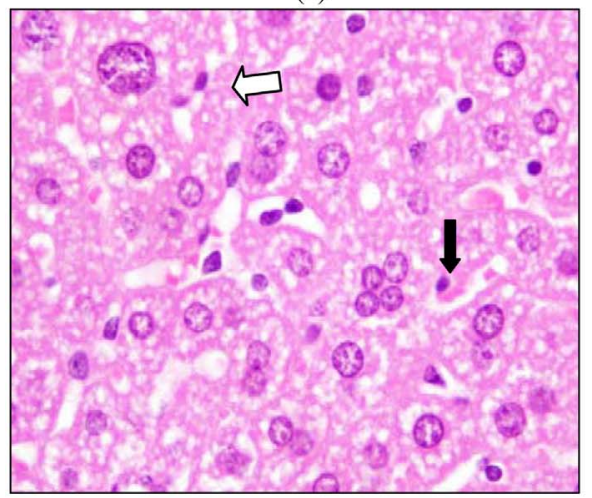

(c)

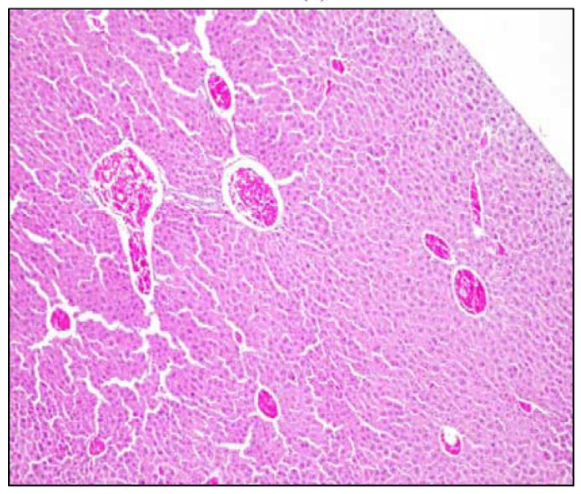

(e)

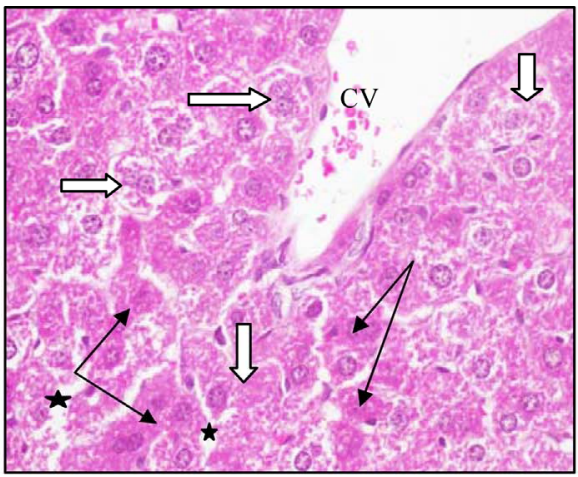

(b)

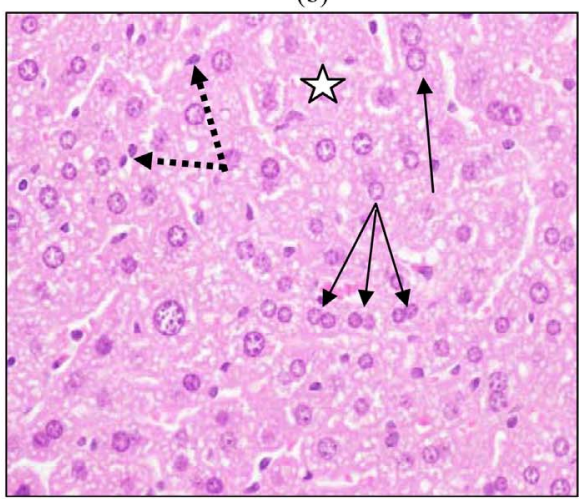

(d)

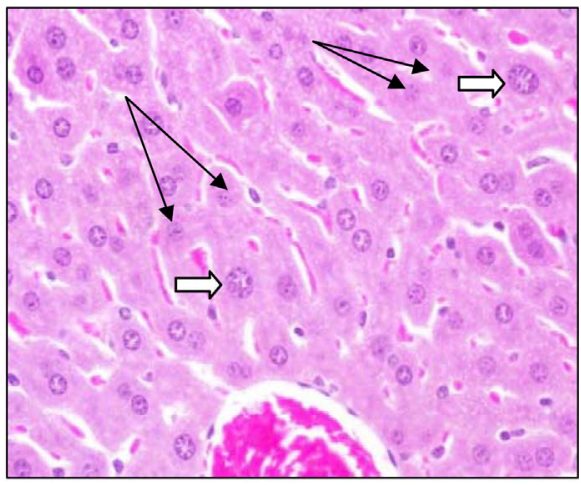

(f)

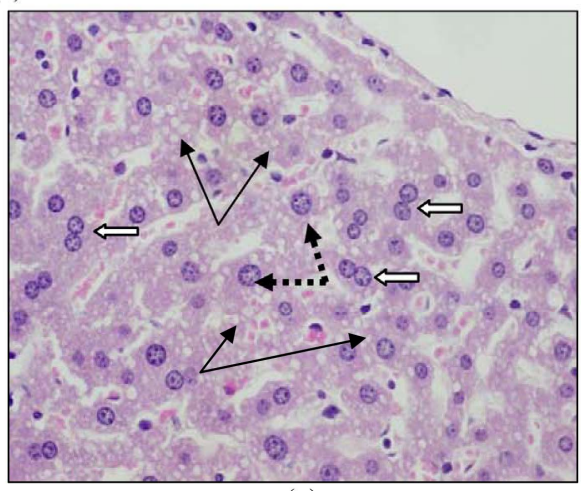

$(\mathrm{g})$

Figure 1. Effect of ZEN (2.7 mg/kg b.w.) on mouse liver and the role of crude venom of jellyfish Cassiopeia andromeda pretreatment. 
hours prior to administration of ZEN twice a week for two weeks showing that hepatocyte cell cords was more or less similar to control expect of the appearance of tiny vacuoles (lipids) within hepatocytes (thinarrows).Same cells showed binucleated cells (white arrow). Others exhibit karyomegaly (dotted arrows).

\section{Discussion}

Fusarium mycotoxins are of wide spread occurrence globally. Intense attention has been focused recently on these toxins including zearalenone [19]. Zearalenone is metabolized in the liver with production of alpha-zearalenol $(\alpha$-ZEN) and beta-zearalenol $(\beta$-ZEN) as essential metabolites. First data were reported on the capability of ZEN to induce liver lesions with subsequent development of hepatocarcinoma and pituitary carcinomas [8]. The low dose of ZEN (2.7 mg/kg b.w.) relative to LD50 (500 mg/kg b.w.) was chosen in this study to examine its effect by single and oral repeated administration in Balb/c micee as a sensitive laboratory model. In the present research, a significant increase in liver enzymes ALT, AST and ALP was observed after 48 hours of oral administration of ZEN. Similar observation was found in the group administered the toxin for two weeks. No significant changes in AST and ALP in animals treated for one week while ALT was found increased. Clinically, measuring transaminases is very important and useful in diagnosis of liver function disorders [20]. This increase in liver enzymes reflected hepatocellular damage. Similar observation was described by Maaroufi et al. [21] and Čonková et al. [22]. The level of Alphafetoprotein in the current study was increased after two weeks. Alphafetoprotein is a specific biomarker for liver cancer which is synthesized mainly in the fetal stage. Normally, no production of this marker occurs in the adult cells, but it can be secreted when these cells transformed to cancer cells. Similar finding was observed by Sell et al. [23] and Abdel-Wahhab et al. [24] who found that aflatoxins feeding to ducks for longer term and rats for 6 days produced an elevation in the level of serum AFP. Our result may be attributed to estrogen like effect of ZEN, because estrogens can interact with specific receptors called estrogen receptors (ER) in the liver and exerting a number of toxic effects, including liver adenomas and hepatocarcinomas $[25,26]$. In this investigation, the level of TNF- $\alpha$ was undetectable in all groups except the group treated twice for one week. Tumor necrosis factor is an important proinflammtory cytokine produced mainly by activated macrophages and in smaller amounts by several other cell types. It also mediates hepatotoxicity in many animal models, especially those involving lipopolysaccharide [27]. Zearalenone has been reported tohave anti-inflammatory action by inhibiting TNF- $\alpha$ production [28].

The present finding disclosed that hepatotoxicity caused by ZEN is not mediated by TNF- $\alpha$ as Sharma et al. [29] found that the hepatotoxicity of Fusarium mycotoxin fumonisin was exacerbated in mice lacking TNF- $\alpha$. Oxidative stress is a disturbance in the balance between pro-oxidants and antioxidants. The concentration of the antioxidants were increased in all ZEN treated groups compared to corresponding controls. The capability of ZEN to cause oxidative stress by inducing lipid peroxidation was demonstrated by Kouadio et al. [30]. Higher serum antioxidants might result as a host response to severe oxidative stress or as a compensating mechanism for depleted antioxidative components [31]. In view of such information, the observed elevation in antioxidant is supported by a recent study conducted by Borutova et al. [32] who found an increase of antioxidant enzyme glutathione peroxidase GPx in the blood of chicken after two weeks of feeding them with diet contaminated with $(8.2 \mathrm{mg} / \mathrm{kg})$ and ZEN $(8.3 \mathrm{mg} / \mathrm{kg})$. Protein electrophoresis has been a proven diagnostic technique to test proteins in serum or plasma in human and animals [33]. Most of serum proteins are synthesized in the liver and its total level in the blood is a main liver function test. The levels of these proteins may change in some cases of diseases or certain types of tissue damage. In the current results, mice given ZEN showed an increase in albumin and $\alpha 1$-globulin levels after 48 hours and one week. Abnormally high albumin level was reported to be associated with dehydration [34]. Similar increase in albumin was found in Fusarium mycotoxicity in pigs by Rotter et al. [35] who attributed this increase to a decrease in water or food intake and stated that is transient. Such explanation could be given to the current result, where ZEN produced initial increase in serum albumin after 48 hours and one week, followed by a decrease in both albumin and $\alpha 1$-globulin. This decrease could be explained by the inhibitory effect of ZEN on protein synthesis as described by Kouadio et al. [30]. On the other side, $\alpha 2$ - and $\beta$-fractions were lower after 48 hours, while $\beta$-globulin was increased after two weeks. Considering the estrogenic action of ZEN, estrogens cause an increase in $\beta$ globulin [36]. The $\gamma$ globulin fraction was decreased by ZEN after 48 hours and two weeks. This finding is in agreement with Abbès et al. [37], who found a decrease in both IgA and IgG immunoglobulin concentrations in mice administered ZEN. In general, the present data confirmed that ZEN and its metabolites have may a direct effect on protein synthesis in the liver. Regarding the group which pretreated with crude venom of Jellyfish twenty 24 hours prior to administration of ZEN 
twice a week for two weeks, the results showed an improvement in liver enzymes, alphafetoprotein and antioxidants concentrations. The coelenterata toxins contain bradykinin and related polypeptides which have a kinin like action [38]. The extracted crude venom from Jellyfish Cassiopea andromeda has been found to activate the liver cells by increasing the metabolic rate [12]. The findings of this study are consistent with previous study by Sancho-Bru et al. [39] who demonstrated that a bradykinin has hepatoprotective effects in rodents. The protective effect of crude venom may be due to its bradykinin content. Several mechanisms may be involved in the ameliorative effect of bradykinin. Bradykinin has been found to enhance prostaglandin synthesis [40] which in turn protects against liver injury [41]. Furthermore, bradykinin stimulates signaling pathways that protect parenchymal cells from apoptosis such as nuclear factor $\kappa \mathrm{B}(\mathrm{NF}-\kappa \mathrm{B})$ and protein kinase B [42]. In the present study, statistical analysis revealed lack of difference in albumin, $\alpha 1$-glo- bulin between ZEN treated group for two weeks and the crude venom pretreated group. This indicates that the crude venom has no effect in recovering the changes induced by ZEN on albumin and $\alpha 1$-globulin synthesis by hepatic cells. However, $\beta$-fraction was near to normal level, while $\gamma$-fraction was increased relative to control and ZEN treated group. This result could be attributed to the effect of the crude venom in enhancing the immune defense. It has been reported that the toxin extracted from the jellyfish Catostylus mosaicus exhibits physiological activity such as autoimmune stimulation by elevation of IgM and $\operatorname{IgG}$ serum levels in humans, and boosting innate immune function [9]. Our finding has shown that the activity relating to the immune system of the crude venom extracted from the jellyfish Cassiopea andromeda exists and the results warrant further investigation.

Biochemical results in the present study showed alteration in ALT, AST and ALP enzymes which pointed to some sort of hepatocytes necrosis observed herein. Similar association between increased level of hepatic enzymes and cell necrosis were described by many investigators especially with mycotoxin hepatotoxicity [37]. Bi- nucleated hepatocytes were also observed after ZEN administration and more frequently after one week. Cells with double or multiple nuclei can arise as a result of nuclear division. DNA replication, mitosis and cytokinesis usually evolve in a coordinated way, and each diploid cell yields two diploid daughters [43]. However, if DNA replication and mitosis occur without cytokinesis, the cell becomes binucleated or if DNA replication occurs without mitosis or cytokinesis, the ploidy of the nucleus doubles [44]. The increased occurrence of binucleate he- aptocytes was hypothesized that they may be an index of the severity of hepatic illness and that binuclearity may be interpreted as a cell state that is more capable of responding to a major demand for protein synthesis. Taken together, it could behypothesized that binucleate hepatocytes may be a reactive cell response to liver injury [45]. Hepatocyte polyploidy which encountered after one week serves as an integral indicator of compensator liver regeneration and its resistance [46]. Jellyfish crude venom was found to ameliorate the toxic effect of ZEN on hepatocytes. The hepatocytes looked more or less similar to control except of the appearance of tiny vacuoles and some binucleated cells. Abdel-Rehim [13] proved a protective effect of this crude venom in the cases of gastric ulceration evoked by indomethacin. The protective role of crude venom may be due to its content of bradykinin [38] which decreases the liver damage through reducing hepatocellular apoptosis [39]. In conclusion, this work confirmed that ZEN caused an alterations in the liver. While, the crude venom extracted from the Jellyfish protected the liver structure and function from the ZEN toxicity. These protective effects of the crude venom may be attributed to many factors such as amino acid content or may result from the activation of endogenous bradykinin or maybe due to the stimulation of prostaglandin release which promoted the protective effects. Further investigation at biochemical, molecular and histological levels are required to clarify the exact mechanism of ZEN hepatotoxicity. Also, how the Jellyfish crude venom antagonizes such toxicity.

\section{REFERENCES}

[1] J. W. Bennet and M. Klich, "Mycotoxins," Clinical Microbiology, Vol. 16, No. 3, 2003, pp. 497-516.

[2] J. K. Miller, A. Hacking, J. Harrison and V. J. Gross, "Stillbirths, Neonatal Mortality and Small Litters in Pigs Associated with the Ingestion of Fusarium Toxin by Pregnant Sows," Veterinary Record, Vol. 93, No. 21, 1973, pp. 555-559. doi:10.1136/vr.93.21.555

[3] C. J. Mirocha, S. V. Pathre, B. Schauerhamer and C. M. Christensen, "Natural Occurrence of Fusarium Toxins in Feedstuffs," Applied and Environmental Microbiology Vol. 32, No. 4, 1976, pp. 553-556.

[4] B. J. Blaney, R. C. Bloomfield and C. J. Moore, "Zearalenone Intoxication of Pigs," Australian Veterinary Journal, Vol. 61, No. 1, 1984, pp. 24-27. doi:10.1111/j.1751-0813.1984.tb07126.x

[5] P. Szuetz, A. Mesterhazy, G. Y. Falkay and T. Bartyok, "Early Telearche Symptoms in Children and Their Relations to Zearalenone Contamination in Food Stuffs," Cereal Research Communications, Vol. 25, 1997, pp. 429436.

[6] T. Kuiper-Goodman, P. M. Scott and H. Watanabe, "Risk 
Assessment of the Mycotoxin Zearalenone," Regulatory Toxicology and Pharmacology, Vol. 7, No. 3, 1987, pp. 253-306. doi:10.1016/0273-2300(87)90037-7

[7] M. Weidenborner, "Encyclopedia of Food Mycotoxins," Springer, Berlin, 2001.

[8] National Toxicology Program, "NTP Carcinogenesis Bioassay of Zearalenone in F344/N Rats and F6C3F1 Mice," Technical Report Series No. 235, Department of Health and Human Resources, Research Triangle Park, 1982.

[9] B. R. Rich and P. A.Cheras, "The Blue Jellyfish-A Promising Autoimmune Stimulant," 2009.

https://rirdc.infoservices.com.au/downloads/09-035.pdf.a u/downloads/09-035.pdf

[10] J. W. Burnett and G. J. Calton, "Sea Nettle and Man O'War Venoms: A Clinical Comparison of Their Venoms and Studies on Their Stings," Journal of Investigative Dermatology, Vol. 62, No. 4, 1974, pp. 372-377. doi:10.1111/1523-1747.ep12701635

[11] S. Abu-Amra and S. A. A. Elrehim, "Stimulation of Some Enzymes and Cellular Proliferation by: Factors Separated from Scorpion and Jellyfish," Journal of the Egyptian German Society of Zoology, Vol. 31, 2000, pp. 273-287.

[12] F. F. Y. Radwan, J. W. Burnett, D. A. Bloom, T. Coliano, M. E. Eldefrawi, H. Erderly, L. Aurelian, M. Torres and E. P. Heimer-de la Cotera, "A Comparison of the Toxinological Characteristics of Two Cassiopea and Aurelia Species," Toxicon, Vol. 39, No. 2-3, 2001, pp. 245-257. doi:10.1016/S0041-0101(00)00121-5

[13] S. A. Abdel-Rehim, "Influence of Extracted Crude Venom of Jellyfish Cassiopea Andromeda on Healing of Experimental Gastric Ulcers in Mice," Journal of the Egyptian German Society of Zoology, Vol. 48, 2005, pp. 257-278.

[14] S. C. Lu and H. Y. Huang, "Comparison of Sulphur Amino Acid Utilization for GSH Synthesis between HepG2 Cells and Cultured Rat Hepatocytes," Biochemical Pharmacology, Vol. 47, No. 5, 1994, pp. 859-869. doi:10.1016/0006-2952(94)90486-3

[15] C. Urani, M. Doldi, S. Crippa and M. Camatini, "Human-Derived Cell Lines to Study Xenobiotic Metabolism," Chemosphere, Vol. 37, No. 14-15, 1998, pp. 27852895. doi:10.1016/S0045-6535(98)00321-X

[16] N. M. El-Sawi, "Effect of Jellyfish Crude Venom on Liver, Thyroid and Harderian Glands of Female Mice," Journal of Applied Animal Research, Vol. 22, 2002, pp. 97-104.

[17] H. B. Waynforth, "Experimental Animal and Surgical Technique in the Rat," Academic Press Inc., Cambridge, 1980.

[18] R. A. Drury and E. A. Wallington, "Calton's Histological Technique,” Oxfortd University Press, Oxford, 1980.

[19] L. L. Charmley, A. Rosenberg and H. L. Trenholm, "Factors Responsible for Economic Losses Due to Fusarium Mycotoxin Contamination of Grains, Foods and Feedstuffs," In: J. D. Miller and H. L. Trenholm, Eds.,
Mycotoxins in Grain: Compounds Other than Aflatoxin, The American Association of Cereal Chemists, Inc., Saint Paul, 1994, pp. 471-486.

[20] J. F. Zilva and P. R. Pannall, "Clinical Chemistry in Diagnosis and Treatment," Lloyd-Luke Ltd., London, 1973.

[21] K. Maaroufi, L. Chekir, E. E. Creppy, F. Ellouz and H. Bacha, "Zearalenone Induces Modification of Haematological and Biochemical Parameters in Rats," Toxicon, Vol. 34, No. 5, 1996, pp. 535-540. doi:10.1016/0041-0101(96)00008-6

[22] E. ČonKová, A. Laciaková, B. Pástorová, H. Seidel and G. Kováč, "The Effect of Zearalenone on Some Enzymatic Parameters in Rabbits," Toxicology Letters, Vol. 121, No. 3, 2001, pp. 145-149. doi:10.1016/S0378-4274(01)00312-5

[23] S. Sell, K. L. Xu, W. E. Huff, L. F. Kabena, R. B. Harvey and H. A. Dunsford, "Aflatoxin Exposure Produces Serum Alphafetoprotein Elevations and Marked Oval Cell Proliferation in Young Male Pekin Ducklings," Pathology, Vol. 30, No. 1, 1998, pp. 34-39. doi: $10.1080 / 00313029800169645$

[24] M. A. Abdel-Wahhab, H. H. Ahmed and M. M. Hagazi, "Prevention of Aflatoxin B1-Initiated Hepatotoxicity in Rat by Marine Algae Extracts," Journal of Applied Toxicology, Vol. 26, No. 3, 2006, pp. 229-238. doi:10.1002/jat.1127

[25] J. D. Yager and J. R. Yager, "Oral Contraceptive Steroids as Promoters of Hepatocarcinogenesis in Female Sprague-Dawley Rats," Cancer Research, Vol. 40, No. 10, 1980, pp. 3680-3685.

[26] A. E. M. Vickers and G. W. Lucier, "Estrogen Receptor, Epidermal Growth Factor Receptor and Cellular Ploidy in Elutriated Subpopulations of Hepatocytes during Liver Tumor Promotion by 17 Ethinylestradiol in Rats," Carcinogenesis, Vol. 12, No. 3, 1993, pp. 391-399. doi:10.1093/carcin/12.3.391

[27] C. A. Bradham, J. Plümpe, M. P. Manns, D. A. Brenner and C. Trautwein, "Mechanisms of Hepatic Toxicity I. TNF-Induced Liver Injury," American Journal of Physiology-Gastrointestinal and Liver Physiology, Vol. 275, No. 3, 1998, pp. G387-G392.

[28] P. Rawlins, T. Mandera, R. Sadeghia, S. Hilla, G. Gammona, B. Foxwellf, S. Wrigleya and M. Moore, "Inhibition of Endotoxin-Induced TNF-a Production in Macrophages by 5Z-7-Oxo-Zeaenol and Other Fungal Resorcylic Acid Lactones," International Journal of Immunopharmacology, Vol. 21, No. 12, 1999, pp. 799-814. doi:10.1016/S0192-0561(99)00047-8

[29] R. P. Sharma, Q. He, V. J. Johnson and K. A. Voss, "Increased Expression of CD95-Ligand and Other Apoptotic Signaling Factors by Fumonisin B1, a Hepatotoxic Mycotoxin, in Livers of Mice Lacking Tumor Necrosis Factor Alpha," Cytokine, Vol. 24, No. 5, 2003, pp. 226-236. doi:10.1016/j.cyto.2003.08.009

[30] J. H. Kouadio, T. A. Mobio, I. Baudrimont, S. Moukha, S. D. Dano and E. E. Creppy, "Comparative Study of Cyto- 
toxicity and Oxidative Stress Induced by Deoxynivalenol, Zearalenone or Fumonisin B1 in Human Intestinal Cell Line Caco-2," Toxicology, Vol. 213, No. 1-2, 2005, pp. 56-65. doi:10.1016/j.tox.2005.05.010

[31] K. L. MacKinnon, Z. Molnar, D. Lowe, I. D. Watson and E. Shearer, "Measures of Total Free Radical Activity in Critically Ill Patients," Clinical Biochemistry, Vol. 32, No. 4, 1999, pp. 263-286. doi:10.1016/S0009-9120(98)00109-X

[32] R. Borutovaa, S. Faixa, I. Plachaa, L. Gresakovaa, K. Cobanovaa and L. Lenga, "Effects of Deoxynivalenol and Zearalenone on Oxidative Stress and Blood Phagocytic Activity in Broilers," Archives of Animal Nutrition, Vol. 62, No. 4, 2008, pp. 303-312.

[33] F. Crivellente, M. Bonato and P. Cristofori, "Analysis of Mouse, Rat, Dog, Marmoset and Human Serum Proteins by Capillary Electrophoresis: Comparison with Agarose Gel Electrophoresis," Veterinary Clinical Pathology, Vol. 37, No. 1, 2008, pp. 73-78. doi:10.1111/j.1939-165X.2008.00008.X

[34] S. R. Vavricka, E. Burri, C. Beglinger, L. Degen and M. Manz, "Serum Protein Electrophoresis: An Underused But very Useful Test," Digestion, Vol. 79, No. 4, 2009, pp. 203-210. doi:10.1159/000212077

[35] B. A. Rotter, B. K. Thompson, M. Lessard, H. L. Trenholm and H. Tryphonas, "Influence of Low-Level Exposure to Fusarium Mycotoxins on Selected Immunological and Hematological Parameters in Young Swine," Fundamental and Applied Toxicology, Vol. 23, No. 1, 1994, pp. 117-124. doi:10.1006/faat.1994.1087

[36] D. F. Settlage, R. M. Nakamura, V. Davajan, K. Kharma and D. R. Mishell, "A Quantitative Analysis of Serum Proteins during Treatment with Oral Contraceptive Steroids," Contraception, Vol. 1, No. 2, 1970, pp. 101-114. doi:10.1016/0010-7824(70)90050-8

[37] S. Abbes, Z. Ouanes, J. B. Salah-Abbes, Z. Houas, R. Oueslati, H. Bacha and O. Othman, "The Protective Effect of Hydrated Sodium Calcium Luminosilicat Against Haematological, Biochemical and Pathological Changes Induced by Zearalenone in Mice," Toxicon, Vol. 47, No. 5, 2006, pp. 567-574. doi:10.1016/j.toxicon.2006.01.016

[38] J. W. Burnett and G. J. Calton, "The Chemistry and Toxicology of Some Venomous Pelagic Coelenterates," Tox- icon, Vol. 15, No. 3, 1977, pp. 177-196. doi:10.1016/0041-0101(77)90044-7

[39] P. Sancho-Bru, R. Bataller, G. Fernandez-Varo, M. Moreno, L. N. Ramalho, J. Colmenero, M. Marí, J. Clária, W. Jiménez, V. Arroyo, D. A. Brenner and P. Ginès, "Bradykinin Attenuates Hepatocellular Damage and Fibrosis in Rats with Chronic Liver Injury," Gastroenterology, Vol. 133, No. 6, 2007, pp. 2019-2028. doi:10.1053/j.gastro.2007.09.023

[40] A. Levant, E. Levy, M. Argamen and S. Fleisher-Berkovich, "Kinins and Neuro Inflammation: Dual Effect on Protaglandin Synthesis," European Journal of Pharmacology, Vol. 546, No. 1-3, 2006, pp. 197-200. doi:10.1016/j.ejphar.2006.06.074

[41] M. Takano, H. Nishimura, Y. Kimura, J. Washizu, Y. Mokuno, Y. Nimura and Y. Yoshikai, "Prostaglandin $E_{2}$ Protects against Liver Injury after Escherichia Coli Infection But Hampers the Resolution of the Infection in Mice," The Journal of Immunology, Vol. 161, No. 6, 1998, pp. 3019-3025.

[42] H. Yin, L. Chao and J. Chao, "Kallikrein/Kinin Protects against Myocardial Apoptosis after Ischemia/Reperfusion via Akt-Glycogen Synthase Kinase-3 and Akt-Bad. 14-3-3 Signaling Pathways," The Journal of Biological Chemistry, Vol. 280, No. 9, 2005, pp. 8022-8030. doi:10.1074/jbc.M407179200

[43] M. Glotzer, "The Molecular Requirements for Cytokinesis," Science, Vol. 307, No. 5716, 2005, pp. 1735-1739. doi:10.1126/science.1096896

[44] P. Gerlyng, A. Abyholm, T. B. E. Grotmol, H. S. Huitfeldt, T. Stokke and P. O. Seglen, "Binucleation and Polyploidization Patterns in Developmental and Regenerative rat Liver Growth," Cell Proliferation, Vol. 26, No. 6, 1993, pp. 557-565. doi:10.1111/j.1365-2184.1993.tb00033.x

[45] F. Grizziand and M. Chiriva-Internati, "Human Binucleate Hepatocytes: Are They a Defense during Chronic Liver Diseases?" Medical Hypotheses, Vol. 69, No. 2, 2007, pp. 258-261. doi:10.1016/j.mehy.2006.12.029

[46] N. N. Beliaeva, "Proliferation and Polyploidy of Hepatocytes as Indicators of Liver Regeneration after Exposure to Environmental Chemical Factors," Gigiena i Sanitariia, Vol. 3, 1989, pp. 48-52. 